\title{
Spatial Distribution and Its Evolution Characteristics of A-grade Scenic spots of Xinjiang in the Context of Big Data
}

\author{
Ding Guijin ${ }^{1, a}$, Wu Jinfeng ${ }^{* 2, b}$,Deng Chunchun ${ }^{3, c}$ \\ ${ }^{1}$ School of Geography and Tourism, Shaanxi Normal University Xi' an, China \\ ${ }^{2}$ School of Geography and Tourism, Shaanxi Normal University Xi' an, China \\ ${ }^{3}$ School of Geography and Tourism, Shaanxi Normal University Xi' an, China
}

\begin{abstract}
In the context of big data, based on the space analysis function in GIS, using the nearest neighbor index, kernel density analysis and the model of gravity center migration, this article studies spatial distribution and its evolution characteristics of A-grade scenic spots. The results showed that: 1) The number of A-grade scenic spots of Xinjiang grows rapidly and the grade structure is constantly optimized. 2) The spatial distribution characteristics of A-grade scenic spots of Xinjiang are as follows: the spatial distribution of scenic spots is in the pattern of "large dispersion and small agglomeration", mainly along $120 \mathrm{~km}$ around the city and $10 \mathrm{~km}$ on both sides of the traffic trunk lines, presenting a "cluster" distribution. 3) The spatial evolution characteristics of A- grade scenic spot in Xinjiang are as follows: the center of gravity of the scenic spot is gradually moving to the west, the overall distribution scope is constantly expanding, and the degree of local agglomeration is constantly increasing, formed three core distribution areas: Urumqi-changji, Yili and Kashgar. 4) The spatial distribution and evolution characteristics of A-grade scenic spots of Xinjiang are mainly affected by topography, the nearby city, population scale and traffic conditions.
\end{abstract}

\section{INTRODUCTION}

Tourism resources are the foundation and prerequisites for the survival and development of tourism, and one element of tourism development. Tourism resources have always been a hotspot of research. The characteristics of spatial pattern evolution not only directly present the local tourism construction and development, but also have a significant impact on the development strategies of regional tourism competition and cooperation ${ }^{[1]}$. The studies on tourist attractions are mainly about scenic spot planning and marketing ${ }^{[2,3]}$, scenic spot evaluation ${ }^{[4,5]}$, tourist behavior of scenic spots ${ }^{[6,7]}$, scenic spot spatial structure and distribution and evolution ${ }^{[8,9]}$. A-grade scenic spots are China's unique evaluation standards for tourism resources, covering most of the high-quality tourism resources. They become the benchmark for Chinese quality tourism products. The characteristics of spatial distribution and evolution of A-grade scenic spots are important in the studies of tourism scenic spots. In recent years, many scholars have carried out a series of studies on them. Chinese scholars' research on the spatial distribution and evolution characteristics of A-grade scenic spots is more focused on certain levels or certain types of A-grade scenic spots ${ }^{[10-12]}$. They generally focused on eastern China ${ }^{[13,14]}$.

As the core area of the Silk Road Economic Belt, Xinjiang has rich tourism resources. Scholars have relatively little research on the spatial distribution of tourism resources and scenic spots of Xinjiang. Existing studies have not well studied the Xinjiang A-grade scenic spots. These characteristics presented on the provincial scale are relatively macro and general, and lack in-depth analysis. Therefore, there is a lack of targeted development suggestions based on the researches. Based on the improvement of the scenic spot data, this paper studied the characteristics of spatial distribution and evolution of Xinjiang's A-grade scenic spots by the nearest neighbor index, kernel density analysis and the model of gravity center migration, and further discussed the influencing factors.

\section{DATA SOURCES AND RESEARCH METHODS}

\subsection{Data sources}

We selected the data of Xinjiang A-grade scenic spots in 2007, 2012, and 2017 (including the Xinjiang Production and Construction Corps), and the list of scenic spots comes from "China Tourism Scenic Spot Development Report", "Xinjiang Yearbook", "Bingtuan Yearbook" and Xinjiang Tourism Official Website. According to the classification and evaluation method of tourism resources in the "Tourism Resources Classification, Investigation and Evaluation" (GB / T18972-2003), China National

aEmail: 278125866@qq.com

*bEmail: jfwu@snnu.com.cn

'Email: 840432561@qq.com 
Standards and "China Tourism Resources Classification System and Type Evaluation" [15], we classified Xinjiang A-grade scenic spots as natural scenic spots and humanistic scenic spots. In addition, they were divided into high-grade scenic spots (4-5A) and low-grade scenic spots (1-3A).

\subsection{Research methods}

\subsubsection{Nearest neighbor index}

The nearest neighbor point index is a method of measuring the distribution of actual point elements based on the random distribution of point elements ${ }^{[16]}$, presenting the spatial concentration of point elements. The calculation formula is

$$
\begin{gathered}
R=\frac{\overline{r_{l}}}{\overline{r_{E}}} \\
\overline{r_{E}}=\frac{1}{2 \sqrt{D}}=\frac{1}{2 \sqrt{n / A}}
\end{gathered}
$$

where $\mathrm{R}$ is the nearest neighbor index. When $\mathrm{R}=1, \mathrm{~A}-$ grade scenic spots are randomly distributed. When $\mathrm{R}>1$, the A-level scenic spots are evenly distributed. When $\mathrm{R}<1$, the A-level scenic spots are clustered. $\bar{r}_{l}$ is the actual average nearest distance of A-grade scenic spots. $\overline{r_{E}}$ is the theoretical average nearest distance of A-grade scenic spots. $\mathrm{A}$ is the area of the research region; $\mathrm{n}$ is the number of A-grade scenic spots; D is the density of A-grade scenic spots.

1) Kernel density analysis

Kernel density analysis is an effective method to estimate the number of statistical points within a certain

neighborhood. This reveal the spatial distribution of resources in a visual form ${ }^{[9]}$. The formula is

$$
\mathrm{f}_{h}(\mathrm{x})=\frac{1}{n h} \sum_{i=1}^{n} K\left(\frac{x_{i}-x}{h}\right), x \in R
$$

where $f_{h}(x)$ is the estimate value of kernel density analysis; $\mathrm{n}$ is the number of points in the neighborhood; $\mathrm{h}$ is the bandwidth; $\mathrm{K}(*)$ represents the kernel function. In this paper, we looked for the dense areas in the spatial distribution of the scenic spots through the kernel density analysis. This made the spatial distribution can be visualized.

\subsubsection{The model of gravity center migration}

The gravity center migration model was used to calculate the distribution center of gravity of Xinjiang A-grade scenic spots in different periods. This described the overall change trend and spatial variation characteristics of Agrade scenic spots in different periods through the model of gravity center migration [17]. The gravity center migration formula is

$$
X_{t}=\frac{\sum_{i=1}^{n} x_{i}}{n} ; Y_{t}=\frac{\sum_{i=1}^{n} y_{i}}{n}
$$

where $X_{t}$ and $Y_{t}$ are the latitude and longitude coordinates of gravity center migration of the A-grade scenic spots of Xinjiang in different periods; $n$ is the number of A-grade scenic spots; $x_{i} 、 y_{i}$ are the geometric center coordinates of the i-th A-grade scenic spot in different periods.

\begin{tabular}{|c|c|c|c|c|c|c|c|c|c|}
\hline & \multicolumn{2}{|c|}{2007} & \multicolumn{2}{|c|}{2012} & \multicolumn{2}{|c|}{2017} & \multicolumn{3}{|c|}{ Mean annual rate $(\%)$} \\
\hline & number & $\begin{array}{c}\text { weight } \\
(\%)\end{array}$ & number & $\begin{array}{c}\text { weight } \\
(\%)\end{array}$ & number & $\begin{array}{c}\text { weight } \\
(\%)\end{array}$ & $\begin{array}{c}2007 \\
-2012 \\
\end{array}$ & $\begin{array}{c}2012 \\
-2017 \\
\end{array}$ & $\begin{array}{c}2007 \\
-2017 \\
\end{array}$ \\
\hline A-grade & 165 & 100.00 & 280 & 100.00 & 390 & 100.00 & 11.16 & 6.85 & 8.98 \\
\hline natural & 53 & 32.12 & 102 & 36.43 & 124 & 31.79 & 13.99 & 3.98 & 8.87 \\
\hline humanity & 112 & 67.88 & 178 & 63.57 & 266 & 68.21 & 9.71 & 8.37 & 9.04 \\
\hline $5 \mathrm{~A}$ & 3 & 1.82 & 5 & 1.79 & 12 & 3.08 & 10.76 & 19.14 & 14.87 \\
\hline $4 \mathrm{~A}$ & 16 & 9.70 & 54 & 19.29 & 90 & 23.08 & 27.54 & 10.76 & 18.85 \\
\hline $3 \mathrm{~A}$ & 70 & 42.42 & 99 & 35.36 & 162 & 41.54 & 7.18 & 10.35 & 8.75 \\
\hline $2 \mathrm{~A}$ & 50 & 30.30 & 107 & 38.21 & 119 & 30.51 & 16.43 & 2.15 & 9.06 \\
\hline $1 \mathrm{~A}$ & 26 & 15.76 & 15 & 5.36 & 7 & 1.79 & -10.42 & -14.14 & -12.30 \\
\hline
\end{tabular}

\section{RESULTS ANALYSIS}

\subsection{The number of scenic spots}

Table1. The number of A-grade scenic spots of Xinjiang in different periods.

In Table 1, the number of Xinjiang's A-grade scenic spots was increased 115 during 2007-2012, with an average annual growth rate of $11.6 \%$. From 2012 to 2017, the growth rate was 110 , with an average annual growth rate of $6.85 \%$. Although the growth rate in the five years were not differ much, the growth rate decreased significantly. The number of natural scenic spots increased from 2007 to 2012 with 49 , with an average annual growth rate of $13.99 \%$. From 2012 to 2017 , the growth rate was 22, with an average annual growth rate of $3.98 \%$. Both the amount of growth and the growth rate decreased significantly. The number of humanistic scenic spots increased 66 from 2007 to 2012 , with an average annual growth rate of $9.71 \%$. From 2012 to 2017, the growth rate was 88, with an average annual growth rate of $8.37 \%$. The amount of growth was increased, but the growth rate decreased slightly. Overall, Xinjiang's A-grade scenic spots grew faster in 2007-2017, and the proportion of cultural scenic spots was always higher than that of natural scenic spots. The former was about twice that of the latter. It is worth noting that natural scenic spots account for a relatively high proportion of high-level scenic spots. For example, 
there were 102 high-level scenic spots in 2017, including 52 natural scenic spots, $125 \mathrm{~A}$ scenic spots, and as many as 10 natural scenic spots. The "Statistical Analysis Report on Culture and Tourism Development" in 2019 shows that the largest reason for attracting tourists from Xinjiang is the natural beauty of Damei (41.42\%), followed by unique cultural and folk customs $(24.80 \%)$. The natural scenic spots are more attractive among the well-known scenic spots of Xinjiang.

Table2. The nearest neighbor index of A-grade scenic spots.

\begin{tabular}{cccccccccccccccc}
\hline Year & A-grade & Natural & Humanistic & $5 \mathrm{~A}$ & $4 \mathrm{~A}$ & $3 \mathrm{~A}$ & $2 \mathrm{~A}$ & $1 \mathrm{~A}$ & South Xinjiang & North Xinjiang \\
\hline 2007 & 0.373 & 0.599 & 0.348 & 0.664 & 0.661 & 0.425 & 0.360 & 0.650 & 0.349 \\
2012 & 0.436 & 0.634 & 0.322 & 0.760 & 0.619 & 0.469 & 0.467 & 0.407 & 0.406 \\
2017 & 0.414 & 0.671 & 0.329 & 0.649 & 0.606 & 0.450 & 0.444 & 0.392 & 0.354 \\
\hline
\end{tabular}

In Table 2, that, the nearest neighbor index of Xinjiang A-grade scenic spots was $0.373,0.436$ and 0.414 in 2007, 2012 and 2017 respectively, and all of them was less than 1. The A-grade scenic spots showed agglomeration distribution in the three periods, and the degree of agglomeration first decreased and then increased. From the perspective of different types of scenic spots, the nearest neighbor index of natural and humanities scenic spots is also less than 1 . In the three periods, there is agglomeration distribution, in which the nearest neighbor index of natural scenic spots is larger than that of humanistic scenic spots in the same period. From the perspective of different levels of scenic spots, the nearest neighbor index of 1-5A scenic spots is also less than 1. In the three periods, there is agglomeration distribution, and the nearest neighbor index of $4 \mathrm{~A}$ and $5 \mathrm{~A}$ scenic spots is higher than that of 1-3A scenic spots. Therefore, the concentration of high-grade scenic spots is lower than that of low-grade scenic spots. In addition, in the three periods, the spatial agglomeration of A-grade scenic spots in southern Xinjiang was always higher than that in northern Xinjiang.

\subsection{Spatial distribution density of scenic spots}

To study the changes in the spatial pattern of A-grade scenic spots of Xinjiang, we used ArcGIS 10.2 tools to analyze the spatial nuclear density of A-grade scenic spots in 2007, 2012 and 2017. The results are shown in Figure 1 .
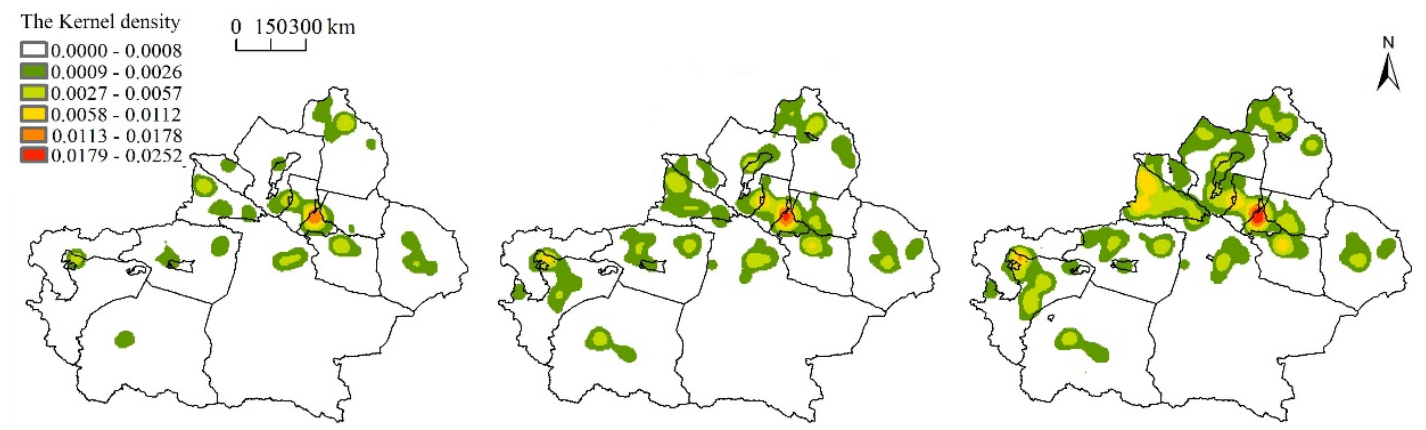

Fig 1. The Kernel density distribution of A-grade attractions in Xinjiang. 


\subsection{Gravity center migration model of scenic spots}

Using ArcGIS 10.2 tools, the spatial distribution of gravity center migration of A-grade scenic spots of Xinjiang in 2007, 2012 and 2017 were calculated according to formula (4). The spatial distribution was shown in Figure 2.

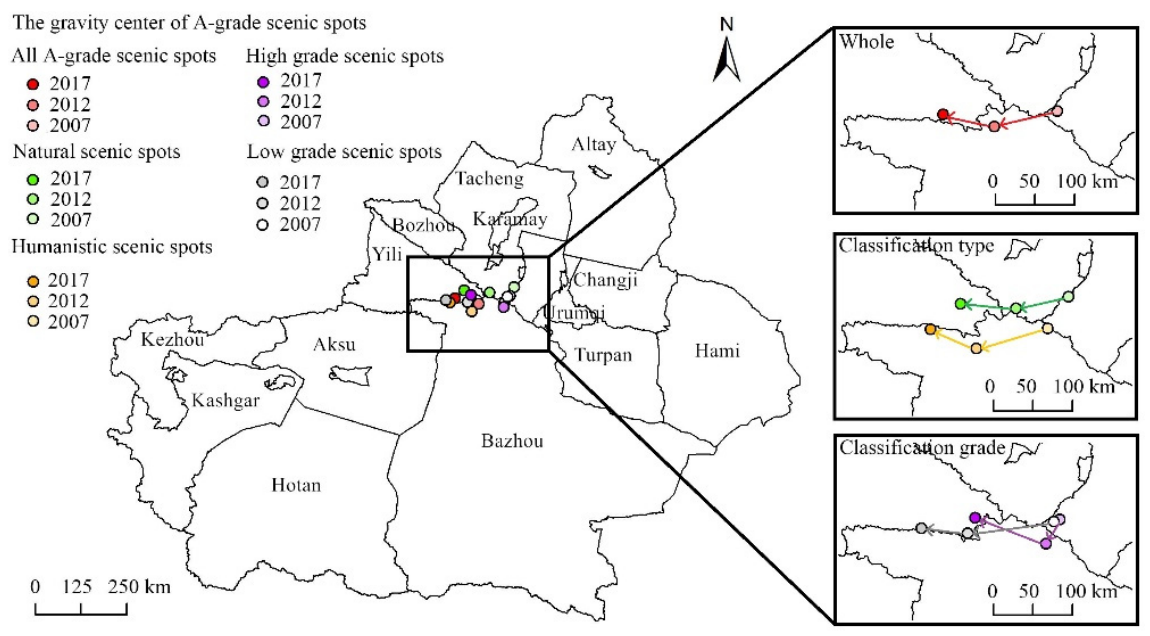

Fig 2. The movement of gravity center of A-grade scenic spots.

The gravity center of A-grade level scenic spot in 2007 was located in Manas County, Changji State $\left(85^{\circ} 46^{\prime} 33\right.$ "E, $\left.43^{\circ} 36 ' 32 N\right)$. In 2012, it moved southwest to Bazhou and Jing County ( $84^{\circ} 50^{\prime} 24$ "E, $43^{\circ} 14^{\prime} 51^{\prime \prime}$ N). In 2017, it moved westward to Xinyuan County, Ili ( $83^{\circ} 59^{\prime} 8$ "E, $\left.43^{\circ} 13^{\prime} 48^{\prime \prime} \mathrm{N}\right)$. In Figure 2, the gravity center of Xinjiang A-grade scenic spots gradually shifted westward from 2007 to 2017. This is because A-grade scenic spots in western Xinjiang have increased since 2007, and the growth rate is faster. For example, there were $15 \mathrm{~A}$-grade scenic spots in Yili in 2007, which increased to 72 in 2017. There were 10 A-grade scenic spots in Kashgar in 2007, and it increased to 46 in 2017. The average annual growth rates are $16.98 \%$ and $16.49 \%$ respectively. Both of them exceeded the average annual growth rate of $8.98 \%$ for Xinjiang A-grade scenic spots. As a result, the gravity center of the scenic spot shifted westward. From different types grades of scenic spots, the gravity center also shifted westward during 2007-2017, and the movement is similar to that of A-grade scenic spots of Xinjiang.

\section{FACTORS OF THE SPATIAL DISTRIBUTION OF SCENIC SPOTS}

\subsection{Topography}

According to altitude statistics of A-grade scenic spots of Xinjiang in 2017, all scenic spots are distributed between $155-4534 \mathrm{~m}$ above sea level, with an average altitude of $1092 \mathrm{~m}$. In terms of different types, natural scenic spots are distributed at the altitude from $155-4534 \mathrm{~m}$, with an average altitude of $1341 \mathrm{~m}$. The humanistic scenic spots are distributed from 24-3098m above sea level, with an average altitude of $975 \mathrm{~m}$. We found that most of the natural scenic spots are distributed along the three major mountains, based on geological landscape, water scenery and biological landscape. Humanistic scenic spots are mainly distributed around the oasis belts on the edge of the two major basins, based on ruins, buildings and facilities, and cultural activities. Therefore, tourism resources are restricted by the geographical environment. Natural factors such as topography and landscape have an great influence on the spatial distribution of A-grade scenic spots.

\subsection{Neighboring cities}

There are 28 cities in Xinjiang, including 4 prefecturelevel cities and 24 county-level cities. We built buffer zones in 28 cities, and overlay the buffer zone with the distribution map of A-grade scenic spots of Xinjiang in 2017. A-grade scenic spots of Xinjiang are distribution around the city. 54\% of A-grade scenic spots are within 60 $\mathrm{km}$ of the city, where $42 \%$ are natural scenic spots and $60 \%$ are cultural scenic spots. There are $80 \%$ of A-grade scenic spots within $120 \mathrm{~km}$ of the city, where $73 \%$ are natural scenic spots and $83 \%$ are humanistic scenic spots. A-grade scenic spots of Xinjiang are mainly cluster distributed within $120 \mathrm{~km}$ of the city, and the humanistic scenic spots have a closer spatial relationship with neighboring cities.

\subsection{Population}

We used SPSS software to perform the correlation analysis between the A-grade scenic spots and population in 14 cities of Xinjiang in 2017. The Pearson correlation coefficient was 0.63 , and the $P$ value was less than 0.05 , indicating a significant positive correlation between them. The operation and development of tourist attractions require sufficient number of tourists. Tourists tend to choose closer tourist destinations to visit ${ }^{[18]}$. The population in the tourist area is an important source. 


\subsection{Transportation}

In the study of national highways, provincial highways, railways and other transportation lines in Xinjiang, we superimposed the buffer zone with the distribution map of A-grade scenic spots of Xinjiang in 2017. 330 A-grade scenic spots are distributed in the buffer zone within $10 \mathrm{~km}$ from the road of scenic spots, accounting for $85 \%$ of all A-grade scenic spots in Xinjiang. The convenience of transportation is not only a necessary condition for the development and construction of tourist attractions, but also an important indicator to estimate the level tourism development [19]. Tourist traffic is one of the most important indicators of the A-grade scenic spot. The construction of A-grade scenic spots is highly dependent on traffic conditions. In addition, A-grade scenic spots, especially high-grade scenic spots, can promote the construction and improvement of infrastructure such as traffic roads.

\section{CONCLUSION}

(1) The number of A-grade scenic spots in Xinjiang has increased rapidly and the hierarchical structure has been continuously optimized. The proportion of natural scenic spots in high-grade scenic spots is relatively high. Compared with the number during 2007-2012, the growth rate of all scenic spots in 2012-2017 has not changed much, but the growth rate has decreased significantly. Among them, the increased amount and growth rate of natural scenic spots have declined. Overall, the number of Agrade scenic spots in Xinjiang grew faster in 2007-2017, the overall quality of scenic spots has been improved.

(2) The spatial distribution characteristics of A-grade scenic spots in Xinjiang are "large dispersion and small agglomeration". They are mainly distributed in a "clustered" shape within the $120 \mathrm{~km}$ around the city, and $10 \mathrm{~km}$ on both sides of the main road of transportation. In 2007, 2012 and 2017, A-grade scenic spots in Xinjiang all showed agglomeration distribution, and the degree of agglomeration first decreased and then increased. Over 70\% of the spatial agglomeration of A-grade scenic spots in Dizhou has decreased. The number of A-grade scenic spots in southern Xinjiang is less than that in northern Xinjiang, and the spatial agglomeration of scenic spots is higher than that in northern Xinjiang.

(3) The spatial evolution characteristics of Xinjiang Agrade scenic spots are that the gravity center of the scenic spot gradually moved westward, and the overall dispersion scope continued to expand. The degree of local agglomeration continues to increase, forming the three core distribution areas of Urumqi-Changji, Yili and Kashgar. From 2007 to 2017, the gravity center of Xinjiang A-grade scenic spots moved west from Manas County in Changji State to Xinyuan County in Ili State. This indicates that the construction of A-grade scenic spots in western Xinjiang has been rapid since 2007. The spatial distribution of scenic spots is not only "large dispersion and small agglomeration", but the overall distribution range is constantly expanding. The degree of local agglomeration continues to increase, continuously promoting the three core distribution areas of UrumqiChangji, Yili and Kashgar.

(4) The characteristics of spatial distribution and evolution of A-grade scenic spots of Xinjiang are mainly affected by factors such as topography, neighboring cities, population size and traffic conditions.

\section{ACKNOWLEDGMENTS}

This work is supported by the National Natural Science Foundation of China (No. 41671135) and the Fundamental Research Funds for the Central Universities (No. 2017TS113).

R. B. G. thanks the National Natural Science Foundation of China (No. 41671135) and the Fundamental Research Funds for the Central Universities (No. 2017TS113).

\section{REFERENCES}

1. Yang, Y.B.; Wang, R.C.; Li, Q.Y.; Cao, H.H. The Evolution Characteristics of Tourism Resources Endowment in Northeast China and Its Industry Space Refactoring. Economic Geography. 2015, 35, 194-201.

2. Taylor, P. What factors make rail trails successful as tourism attractions? Developing a conceptual framework from relevant literature. Journal of Outdoor Recreation \& Tourism. 2015, 12, 89-98.

3. Sammy C.H.L.; Robinson, P.; Oriade, A. Destination marketing: The use of technology since the millennium. Journal of Destination Marketing \& Management. 2017, 6, 95 - 102.

4. Alaeddinoglu, F, Can, A.S. Identification and classification of nature-based tourism resources: Western Lake Van basin, Turkey. Procedia - Social and Behavioral Sciences. 2011, 19, 198-207.

5. Zare, S.; Hasheminezhad, N.; Sarebanzadeh, K.; Zolala, F.; Hemmatjo, R.; Hassanvand, D. Assessing thermal comfort in tourist attractions through objective and subjective procedures based on ISO 7730 standard: A field study. Urban Climate. 2018, 26, 1-9.

6. Versichele, M.; Groote, L. D.; Bouuaert, M.C.; Neutens, T.; Moerman, I.; Weghe, N.V.D. Pattern mining in tourist attraction visits through association rule learning on Bluetooth tracking data: A case study of Ghent, Belgium. Tourism Management. 2014, 44, 67-81.

7. Watthanaklang, D.; Ratanavaraha, V.; Chatpattananan, V.; Jomnonkwao, S. Measuring the motivation to ride bicycles for tourism through a comparison of tourist attractions. Transport Policy. 2016, 52, 153-163.

8. Wang, H.Q.; Yuan, J.D.; Meng, X.J. Spatial Distribution and Its Influencing Factors of Level-A Scenic Spots in Northeast China. Scientia Geographica Sinica. 2017, 37, 895-903. 
9. Wu, C.T.; Li, L.J.; He, X.H.; Wang, J.E. Spatial analysis of scenic spots in the Yangtze River Economic Belt. Resources Science. 2018, 40, 11961208.

10. Wu, B.H.; Yu, X.; Dang, N. The Tendency of Themed Scenic Spots Development in China: A Statistics and Analysis on National A Grade Scenic Spots. Geography and Geo -Information Science. 2006, 22, 89-93.

11. Xiao, W.S. Research on the Spatial Pattern Evolution of the China's national 5A Tourism Attractions. Central China normal university: Wuhan, China, 2015.

12. Li, P.; Yu, H.; Wang, Y.J. Spatial Agglomeration Characteristics of from 3A-class to 5A-class Scenic Spots in China. Scientia Geographica Sinica. 2018, 38, 1883-1891.

13. Mao, X.G.; Song, J.P.; Yu, W. Space structure and its evolution of A-grade tourist attractions in Beijing. Economic Geography. 2011, 31, 1381-1386.

14. Wu, L.M.; Huang, Z.F.; Zhou, W.; Fang, Y.L. The Spatiotemporal Evolution and Dynamic Mechanism of A-Grade Tourist Attractions in Jiangsu Province. Economic Geography. 2013, 33, 158-164.

15. Guo, L.X.; Wu, B.H.; Liu, F.; Fan, Y.Z. Study on the tourist resources classification system and types evaluation in China. Acta Geographica Sinica. 2000, 55, 294-301.

16. Lin, B.Y. Introduction to quantitative geography; Higher education press: Beijing, China, 1986.

17. Li, C.L.; Zhang, W.X. A study of tourist destination image perception in Xinjiang based on online travel notes. Finance \& Economics of Xinjiang. 2015, 03, 73-80.

18. Sun, G.N.; Zhang, Y.; Xue, J. Scenery attraction, location accessibility and trade connection: Three factors and their influences on destination choice of Japanese tourists. Geographical Research. 2011, 30, 1032-1043.

19. Bao, J.G.; Chu, Y.F. Tourist geography; Higher education press: Beijing, China, 1999. 